\title{
The glyceraldehyde-3-phosphate dehydrogenase polypeptides encoded by the Saccharomyces cerevisiae TDH1, TDH2 and TDH3 genes are also cell wall proteins
}

\author{
M. Luisa Delgado, ${ }^{1}$ José E. O'Connor, ${ }^{2}$ Inmaculada Azorín, ${ }^{3}$ \\ Jaime Renau-Piqueras, ${ }^{3}$ M. Luisa Gil ${ }^{1}$ and Daniel Gozalbo ${ }^{1}$
}

Author for correspondence: Daniel Gozalbo. Tel: +34 96398 3026. Fax : +34 963864299. e-mail: daniel.gozalbo@uv.es

1,2 Departamentos de Microbiología y Ecología1, and Bioquímica y Biología Molecular2, Universitat de València, Avda Vicent Andrés Estellés $\mathrm{s} / \mathrm{n}, 46100$ Burjasssot (Valencia), Spain

3 Sección de Biología y Patología Celular, Centro de Investigación, Hospital la $\mathrm{Fe}^{3}$, Valencia, Spain
The authors show that the glycolytic enzyme glyceraldehyde-3-phosphate dehydrogenase (GAPDH) of Saccharomyces cerevisiae, previously thought to be restricted to the cell interior, is also present in the cell wall. GAPDH activity, proportional to cell number and time of incubation, was detected in intact wild-type yeast cells. Intact cells of yeast strains containing insertion mutations in each of the three structural TDH genes (tdh1, tdh2 and tdh3) and double mutants (tdh1 tdh2 and $t d h 1 t d h 3$ ) also displayed a cell-wall-associated GAPDH activity, in the range of parental wild-type cells, although with significant differences among strains. A cell wall location of GAPDH was further confirmed in wild-type and toh mutants by indirect immunofluorescence and flow cytometry analysis with a polyclonal antibody against S. cerevisiae GAPDH. By immunoelectron microscopy, the GAPDH protein was detected at the outer surface of the cell wall of wild-type cells, as well as in the cytoplasm. Western immunoblot analysis of cell wall extracts and cytosol showed that Tdh2 and Tdh3 polypeptides are present in the cell wall, as well as in the cytosol, of exponentially growing cells. Tdh1 is only detected in stationary-phase cells, again in both cytosol and cell wall extracts. The results incorporate the GAPDH of S. cerevisiae, encoded by TDH1-3, into the newly emerging family of multifunctional cell-wall-associated GAPDHs which retain their catalytic activity.

Keywords: insertion mutations, yeast, cell surface, glycolytic enzymes, immunodetection

\section{INTRODUCTION}

Glyceraldehyde-3-phosphate dehydrogenase (GAPDH) has been considered a classical cytosolic glycolytic protein; however, recent evidence demonstrates that mammalian GAPDH displays diverse activities that are unrelated to glycolysis in different subcellular locations (Sirover, 1997, 1999). In some microbial species, including bacteria and yeast, and in the pathogenic helminth Schistosoma mansoni, GAPDH has been found on the cell surface, where it may have differing roles.

\footnotetext{
Abbreviations: G3-P, glyceraldehyde 3-phosphate; GAPDH, glyceraldehyde-3-phosphate dehydrogenase; IIF, indirect immunofluorescence; $\beta$ ME, $\beta$-mercaptoethanol; pAb anti-SC-GAPDH, polyclonal antibody against $S$. cerevisiae GAPDH.
}

The surface GAPDH of Schis. mansoni has been associated with human resistance to schistosomiasis (Charrier-Ferrara et al., 1992; Goudot-Crozel et al., 1989). In group A streptococci and in Staphylococcus aureus a cell-surface GAPDH is involved in the interaction with host cells and ligands (Modun \& Williams, 1999; Pancholi \& Fischetti, 1992, 1993, 1997; Winram \& Lottenberg, 1996, 1998). Also eukaryotic micro-organisms contain a cell-wall-associated GAPDH; in Kluyveromyces marxianus cellular flocculation depends on the expression of a cell-surface GAPDH (Falcao Moreira et al., 1998; Fernandes et al., 1992). We have previously demonstrated that an immunogenic cell-wall-associated GAPDH is found at the cell surface of Candida albicans in an active form (GilNavarro et al., 1997). Clinical strains of C. albicans 
express this surface antigen both in vitro and in infected tissues (Gil et al., 1999) and, since C. albicans GAPDH is also a fibronectin- and laminin-binding protein, the surface GAPDH could participate in the adhesion of fungal cells to host tissues, thus playing a role in virulence (Gozalbo et al., 1998;Villamón et al., 1999).

As most C. albicans genes are functional when expressed in Saccharomyces cerevisiae, we thought it would be interesting to express the cloned C. albicans TDH1 gene, encoding GAPDH (Gil-Navarro et al., 1997), in $S$. cerevisiae cells, to determine whether the gene product is directed to the yeast cell wall in an active form. Unexpectedly, we found that untransformed wild-type intact cells of $S$. cerevisiae possess GAPDH activity. This observation prompted us to determine whether the $S$. cerevisiae GAPDH is also a cell wall protein.

Three unlinked GAPDH structural genes (TDH1-3) are present per haploid S. cerevisiae genome; they encode closely related, but not identical, polypeptides (McAlister \& Holland, 1985a, b). None of the structural genes is individually essential for cell viability; however, the presence of a functional $\mathrm{TDH} 2$ or $\mathrm{TDH} 3$ structural gene is required for cell viability. The three single mutants $t d h 1, t d h 2$ and $t d h 3$, as well as the $t d h 1 t d h 2$ and $t d h 1 t d h 3$ double mutants, can grow using glucose as carbon source, albeit at lower rates (except the $t d h 1$ mutant) than wild-type cells. No growth phenotype has been described for strains lacking only TDH1, and double mutant $t d h 2 t d h 3$ appears not to be viable, indicating that the TDH1 gene product cannot support growth and may carry out a function that is different from glycolysis (McAlister \& Holland, 1985a, b). Synthesis of $\mathrm{Tdh}$ polypeptides is not coordinately regulated; Tdh1 is only synthesized when cells enter stationary phase or in heat-shocked cells, whereas synthesis of Tdh2 is repressed by heat shock (Boucherie et al., 1995).

In the present study, using wild-type strains and single and double $t d h$ mutants, we found that each of the three GAPDH polypeptides encoded by the TDH1-3 genes is associated with the cell wall of $S$. cerevisiae. This enlarges the new emerging family of multifunctional cell-wall-associated GAPDHs which retain their catalytic activity.

\section{METHODS}

Strains used and culture conditions. Two parental (wild-type) isogenic S. cerevisiae strains were used: S173-6B (MATa leu2-

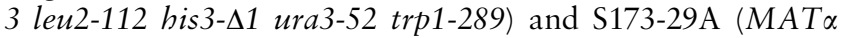
leu2-3 leu2-112 his3- $\Delta 1$ ade1-101 trp1-289); strains LM1, LM5 and LM17, containing insertion mutations in single GAPDH genes $(t d h 1, t d h 2$ and $t d h 3$, respectively), and double mutants LM7 and LM28 (tdh1 $t d h 2$ and $t d h 1 t d h 3$, respectively), constructed by McAlister \& Holland (1985a), were also used. Yeast strains were grown at $28{ }^{\circ} \mathrm{C}$ in YPD medium $(1 \%$ yeast extract, $2 \%$ peptone, $2 \%$ glucose) to the exponential growth phase or to stationary phase.

Generation of polyclonal antibodies against $S$. cerevisiae GAPDH (pAb anti-SC-GAPDH). Female New Zealand White rabbits were immunized with GAPDH from $S$. cerevisiae
(Sigma) according to standard protocols (Harlow \& Lane, 1988). Levels of anti-SC-GAPDH antibodies in sera were determined by ELISA.

Determination of GAPDH activity. The assay for GAPDH activity was carried out according to the method originally described by Ferdinand (1964), with some modifications. An assay for intact whole cells, previously used in C. albicans (Gil-Navarro et al., 1997), was performed to determine the presence of an active GAPDH enzyme at the cell wall of $S$. cerevisiae cells. Triplicate samples of different amounts of exponentially growing cells were incubated with and without glyceraldehyde 3-phosphate (G3-P) (7 $\mu$ l of a solution containing $49 \mathrm{mg}$ substrate $\mathrm{ml}^{-1}$; Sigma) in the presence of NAD (100 $\mu \mathrm{l}$ of a $10 \mathrm{mM}$ solution; Boehringer Mannheim) in assay buffer $\left(40 \mathrm{mM}\right.$ triethanolamine, $50 \mathrm{mM} \mathrm{Na} \mathrm{NPO}_{4}, 5 \mathrm{mM}$ EDTA, $0 \cdot 1 \mathrm{mM}$ dithiothreitol; $\mathrm{pH} 8.6)$ to a final volume of $1 \mathrm{ml}$. After incubation of the reaction mixtures at $28^{\circ} \mathrm{C}$, cells were removed by centrifugation and the supernatants were analysed for the presence of $\mathrm{NADH}$ by recording the absorbance at $340 \mathrm{~nm}$. Background absorbance measured in negative controls (without substrate) were subtracted from positive absorbance values. Activity is expressed as the concentration $(\mu \mathrm{M})$ of NADH generated during the assay. The cytosolic activity was determined in $50 \mu \mathrm{l}$ cytosol sample, and the NADH produced was measured after 10 min of incubation. Specific activity is expressed as nmol NADH $\mathrm{min}^{-1}$ $\mathrm{mg}^{-1}$. Enzyme activities were also determined (as indicated in Results) on cells pretreated with trypsin $\left(250 \mu \mathrm{g} \mathrm{ml} \mathrm{m}^{-1}\right)$ for $30 \mathrm{~min}$ at $37^{\circ} \mathrm{C}$, prior to the enzyme assay, and on cells preincubated with $\mathrm{pAb}$ anti-SC-GAPDH (1:10 dilution), for $30 \mathrm{~min}$ at $37^{\circ} \mathrm{C}$.

Indirect immunofluorescence (IIF) and flow cytometry analysis. Cells from exponentially growing cultures were washed twice with phosphate-buffered saline (PBS), and resuspended at $5 \times 10^{6}$ cells in $50 \mu \mathrm{l} \mathrm{pAb}$ anti-SC-GAPDH, diluted 1:10 in PBS. After $1 \mathrm{~h}$ at $37^{\circ} \mathrm{C}$, cells were washed with PBS and incubated under the same conditions in FITC-conjugated goat anti-rabbit IgG (Pierce, 1:20 dilution) in PBS. After washing with PBS, cells were examined for epifluorescence with a Nikon Eclipse E800 microscope. In flow cytometry analysis, after the immunofluorescence assay, cells were fixed in $1 \%$ paraformaldehyde in PBS, and analysed on an EPICS Elite Cell Sorter (Coulter Electronics), as previously described (Peñalver et al., 1996). Control experiments were performed by omitting incubation of cells with the pAb anti-SC-GAPDH.

Immunoelectron microscopy. Immunoelectron microscopy detection of GAPDH protein in S. cerevisiae S173-29A wildtype cells with the pAb anti-SC-GAPDH was performed by the postembedding method, as previously described (Gozalbo et al., 1998).

Preparation of cell extracts. Protein and glycoprotein components of the walls were released from intact cells by treatment with $\beta$-mercaptoethanol $(\beta \mathrm{ME})$ as previously described (Casanova \& Chaffin, 1991), with minor modifications. Briefly, cells were collected and resuspended in sterile distilled water containing $1 \%(\mathrm{v} / \mathrm{v}) \beta \mathrm{ME}$, and incubated for $30 \mathrm{~min}$ at $37^{\circ} \mathrm{C}$ with shaking. After treatment, the cells were sedimented, and the supernatant fluid was recovered, filtered, and concentrated by freeze-drying ( $\beta \mathrm{ME}$ extract). The $\beta \mathrm{ME}-$ extracted cells were washed with ice-cold PBS, and broken by vortexing with glass beads. After addition of cold PBS, unbroken cells and particulate matter were removed from the supernatant (cytosol) by centrifugation.

Western immunoblotting. Proteins were separated by SDSPAGE (Laemmli, 1970) and electrophoretically transferred to PVDF membranes, using a Trans-Blot cell (Bio-Rad), ac- 
cording to the manufacturer's instructions. Immunodetection was performed using the $\mathrm{pAb}$ anti-SC-GAPDH diluted 1:2000, and peroxidase-conjugated goat anti-rabbit IgG (Bio-Rad, diluted 1:2000); the reactive bands were developed with hydrogen peroxide and 4-chloro-1-naphthol as the chromogenic reagent (Gil-Navarro et al., 1997).

\section{RESULTS}

\section{Detection of GAPDH activity in intact cells of $S$. cerevisiae wild-type and $t d h$ mutants}

We searched for the presence of an active cell-wallassociated form of GAPDH in $S$. cerevisiae cells. Enzymic studies were first carried out with intact cells of parental wild-type strains S173-6B and S173-29A, since the cell-wall-associated GAPDH should catalyse the conversion of G3-P to 1,3-diphosphoglycerate in the presence of inorganic phosphate and NAD, as described in other microbial species (Gil-Navarro et al., 1997; Modun \& Williams, 1999; Pancholi \& Fischetti, 1992). The results revealed GAPDH activity associated with cells of both strains; the activity increased proportionally to cell number, and to the time of enzymic reaction (not shown). Cells from strain S173-29A were two- to threefold more enzymically active than those from strain S173-6B (Fig. 1), although the cytosolic specific activity was similar in both strains (30 and

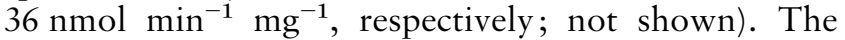
intact cells did not catalyse the formation of NADH in the absence of the substrate (G3-P). The enzymic activity of intact cells was partially inhibited by pAb anti-SCGAPDH (up to $30 \%$ ), and by trypsin treatment $(20-30 \%$ ) (not shown). These results indicate that an

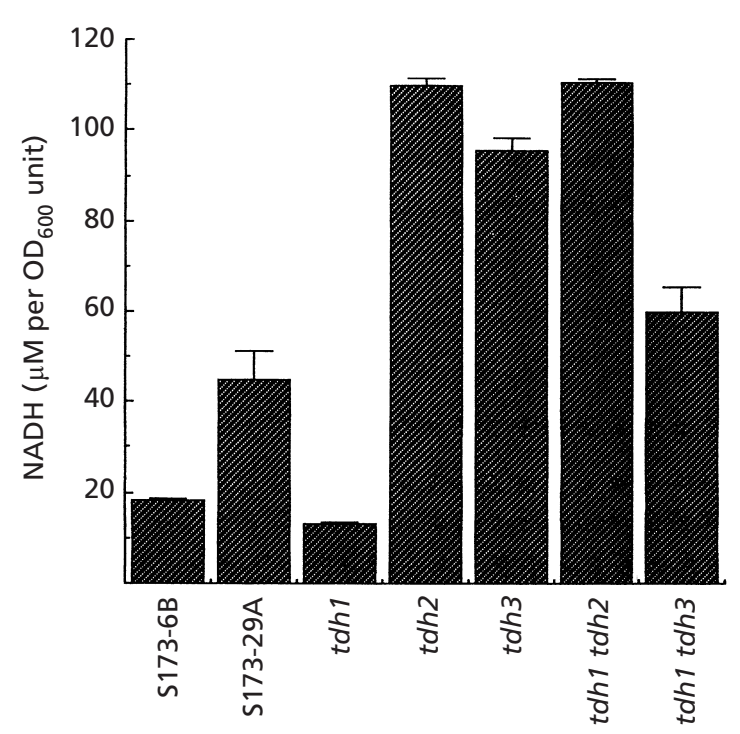

Fig. 1. GAPDH activity in S. cerevisiae wild-type (S173-6B and S173-29A) and tdh mutant cells. Activity was measured in exponentially growing cells collected from $2 \mathrm{ml}$ of cultures, and it is expressed as the ratio of concentration $(\mu \mathrm{M})$ of $N A D H$ formed during the assay $(20 \mathrm{~min})$ and the $\mathrm{OD}_{600}$; data represent triplicate determinations and are expressed as means \pm standard deviations (error bars are not visible on all columns). active GAPDH is associated with the cell wall, partly located at the cell surface, although the activity levels are strain dependent.

To determine whether this cell-wall-associated activity corresponded to one or more TDH gene products, we measured the activity of intact cells of yeast strains containing insertion mutations in each of the three GAPDH structural genes $(t d h 1, t d h 2$ and $t d h 3)$ as well as in double mutant ( $t d h 1 t d h 2$ and $t d h 1 t d h 3)$ strains. The results (Fig. 1) showed that all the mutant strains possessed cell-wall-associated GAPDH activity, in the range of parental wild-type cells, with significant differences among mutants. Cells expressing both TDH2 and TDH3 (tdh1 mutant) had less activity than cells expressing both TDH1 and TDH3 (tdh 2 mutant), TDH1 and TDH2 (tdh3 mutant), and double mutants expressing either TDH2 or TDH3. The cytosolic specific activity of the mutants did not correlate with the levels of cell-wall-associated activity: $t d h 1, t d h 2$ single mutants and the $t d h 1 t d h 2$ double mutant had similar

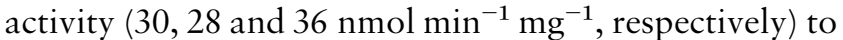
parental wild-type cells, whereas cells lacking TDH3

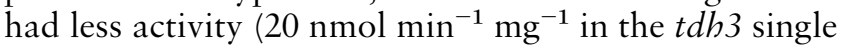
mutant, and $11 \mathrm{nmol} \mathrm{min}^{-1} \mathrm{mg}^{-1}$ in the $t d h 1 \mathrm{tdh} 3$ double mutant). However, $t d h 2$ mutants $(t d h 2$ and $t d h 1$ $t d h 2)$ grew more slowly in the presence of glucose than did $t d h 3$ single and double mutants (doubling time $3.8 \mathrm{~h}$ and $3 \cdot 3$ h respectively); these results agree with previous observations indicating that TDH2 and TH3 may not encode functionally equivalent polypeptides (McAlister \& Holland, 1985a, b).

These results indicate that at least the polypeptides encoded by $\mathrm{TDH} 2$ and $\mathrm{TDH} 3$ are associated with the cell wall in an active form, whereas no conclusion can be deduced regarding TDH1 due to the lack of a $t d h 2 t d h 3$ double mutant.

\section{Immunodetection of GAPDH protein at the surface of S. cerevisiae cells}

$\mathrm{pAb}$ anti-SC-GAPDH was used in an IIF assay to assess the presence of the protein on the surface of intact cells. Fluorescence was detected in most of the cells from both parental wild-type strains and all five $t d h$ mutants by microscopic observation (Fig. 2) and flow cytometry analysis (not shown), indicating that GAPDH polypeptides are exposed on their surface. Labelling intensity was heterogeneously distributed among the cell population, and showed a patchy binding distribution, as previously described in C. albicans blastoconidial cells (Gil-Navarro et al., 1997; Gozalbo et al., 1998). Fluorescence was not observed when the cells were reacted with the second FITC-labelled marker antibody alone, indicating that the reactivity found was dependent on the previous interaction of the specific antibody ( $\mathrm{pAb}$ anti-SC-GAPDH) with cells. This confirms the presence of Tdh2 and Tdh3 at the yeast cell surface.

In addition, we examined parental yeast cells (S173-29A) by immunoelectron microscopy with the pAb anti-SCGAPDH, to show ultrastructural evidence of the cell 

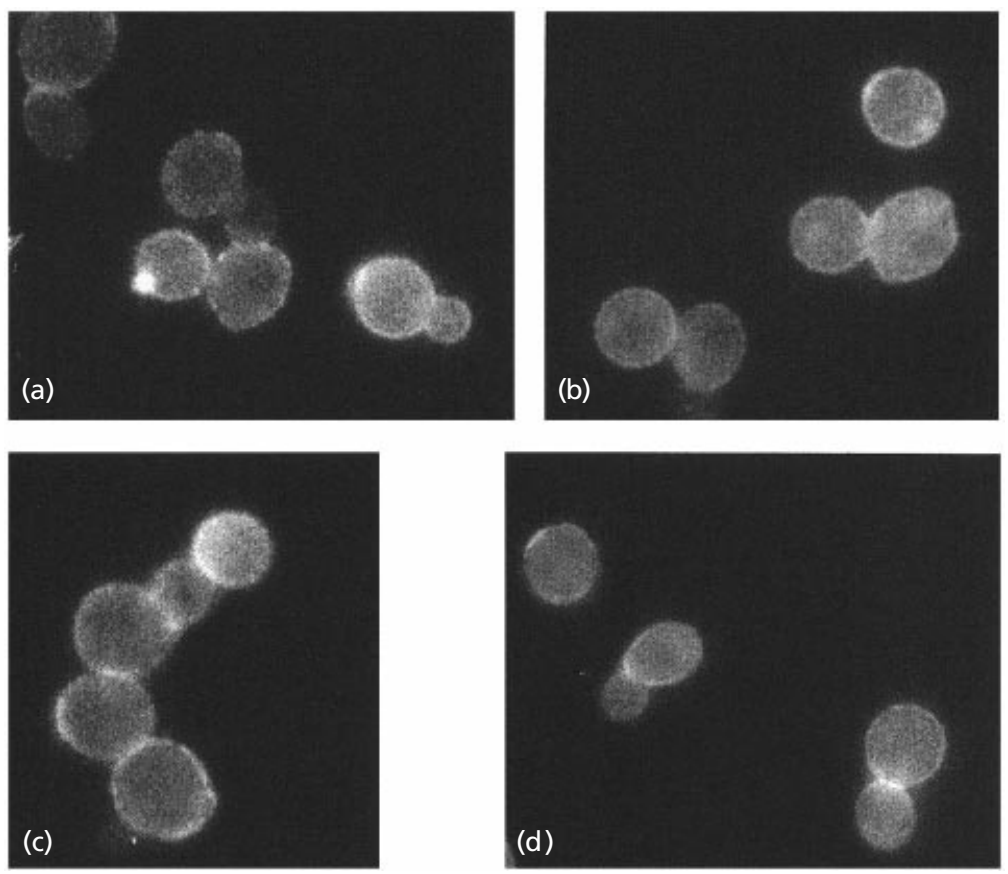

Fig. 2. Surface localization of GAPDH by IIF with pAb anti-SC-GAPDH. Cells of $S$. cerevisiae wild-type strains S173-6B (a) and S173-29A (b), and tdh1 tdh2 (c) and tdh1 tdh3 (d) double mutants were incubated with the pAb anti-SC-GAPDH and FITCconjugated goat anti-rabbit IgG as described in Methods. Microscopic observation under UV illumination (fluorescence).

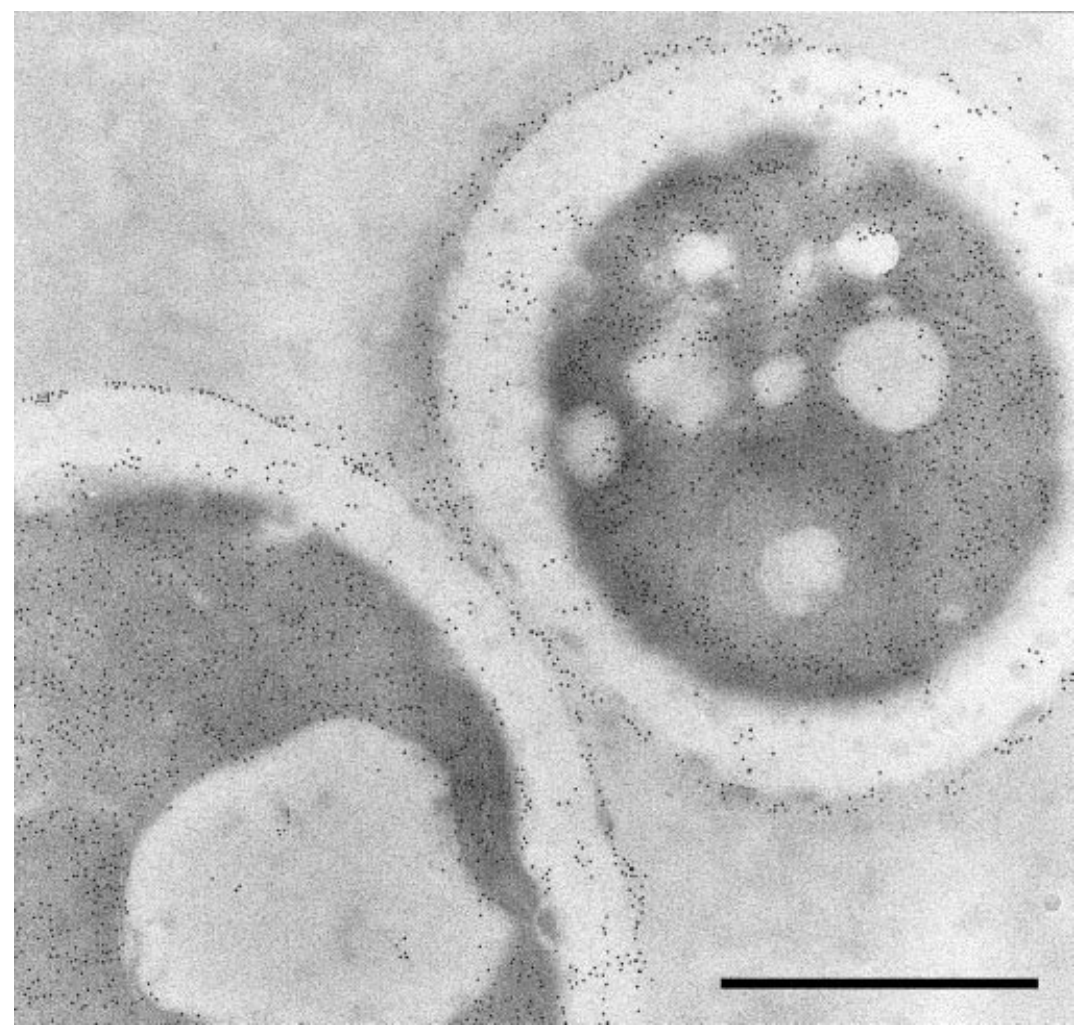

Fig. 3. Immunoelectron microscopy detection of GAPDH protein in S. cerevisiae S17329A wild-type cells by the postembedding method. Labelling was performed using pAb anti-SC-GAPDH. Bar, $1 \mu \mathrm{m}$.

wall location of the GAPDH protein (Fig. 3). Gold particles were distributed over the outermost layer of the cell wall, and extending to a minor extent through the cell wall. The particles were also found distributed throughout the cytoplasm as expected. Control samples not exposed to $\mathrm{pAb}$ anti-SC-GAPDH prior to incubation with the gold-conjugated antibody were free of label (not shown).

\section{Solubilization of cell-wall-associated GAPDH polypeptides from intact cells of $S$. cerevisiae}

To confirm the cell wall location of the GAPDH protein, we searched for the presence of GAPDH in $\beta$ ME extracts obtained from intact $S$. cerevisiae cells. It is well established that these extracts contain bona fide cellsurface molecules (Chaffin et al., 1998; López-Ribot \& 
(a)

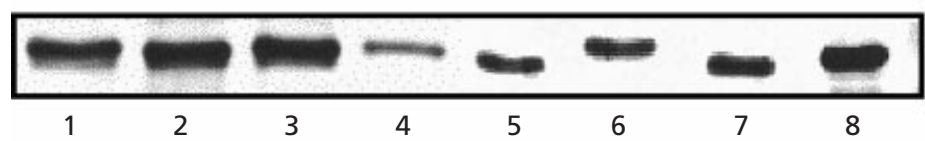

(b)

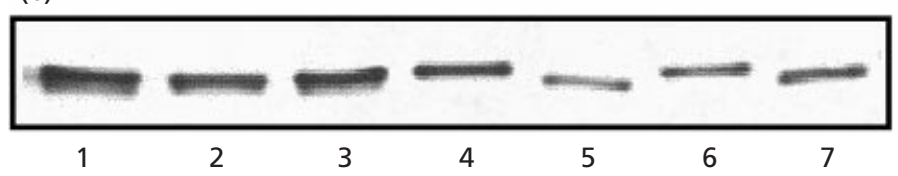

(c)

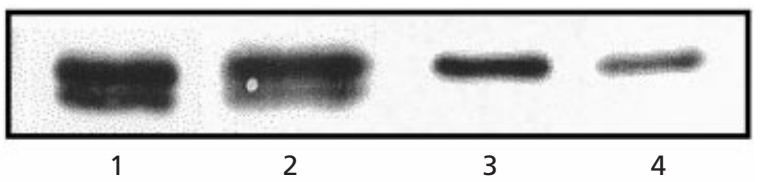

Fig. 4. Immunodetection of Tdh polypeptides by Western immunoblot analysis with the pAb anti-SC-GAPDH. (a) Reactivity of the antibody with the protein present in the $\beta \mathrm{ME}$ extracts obtained from exponentially growing wild-type S173-6B (lane 1) and S173-29A (lane 2) strains, and $t d h 1, t d h 2, t d h 3$ single mutants (lanes 3,4 and 5 , respectively), and tdh1 tdh 2 and tdh 1 tdh 3 double mutants (lanes 6 and 7, respectively); lanes 1-7 each contain $3 \mu \mathrm{g}$ protein extract, and lane 8 contains $0.5 \mu \mathrm{g}$ GAPDH from S. cerevisiae (Sigma). (b) Reactivity of the antibody to cytosol samples from exponentially growing wild-type (S173-6B and S173-29A), and tdh1, tdh2, tdh3, tdh1 tdh2, and tdh1 tdh3 mutant cells (lanes 1-7 respectively); each lane contains $6 \mu \mathrm{g}$ cytosolic protein. (c) Reactivity of the antibody to cytosol (lanes 1 and 3; $6 \mu \mathrm{g}$ protein) and $\beta \mathrm{ME}$ extracts (lanes 2 and $4 ; 3 \mu \mathrm{g}$ protein) from stationary-phase cells of the tdh3 mutant (lanes 1 and 2) and the tdh1 tdh3 double mutant (lanes 3 and 4).

Chaffin, 1996), and this treatment has been used previously to solubilize the cell-wall-associated GAPDH from C. albicans (Gil et al., 1999; Gil-Navarro et al., 1997).

The $\beta \mathrm{ME}$ extracts from exponentially growing cells were analysed by SDS-PAGE and Western blotting using the $\mathrm{pAb}$ anti-SC-GAPDH as a probe. The antibody reacted with the control protein (GAPDH from $S$. cerevisiae, Sigma) and immunodetected a polypeptide(s) with the same apparent molecular mass as the control protein $(36 \mathrm{kDa})$ (Fig. 4a). The presence of soluble GAPDH from $S$. cerevisiae ( $1 \mathrm{mg} \mathrm{ml}^{-1}$, Sigma) in the $\mathrm{pAb}$ preparation used to develop the Western blot inhibited immunodetection of the $36 \mathrm{kDa}$ polypeptide, which further supports the specificity of the reaction. In cells expressing one TDH gene $(t d h 1 t d h 2$ and $t d h 1 t d h 3$ double mutants) only a single polypeptide was detected, corresponding to $\mathrm{Tdh} 3$ and $\mathrm{Tdh} 2$, respectively; Tdh2 migrated slightly faster than Tdh3. This was confirmed by the detection of two polypeptides in $t d h 1$ mutant cells. In parental strains these two polypeptides were also detected, and in $t d h 2$ and $t d h 3$ single mutants only one polypeptide was detected. These data show that Tdh1 is not present in these extracts. This pattern of reactive polypeptides was also found when the immunoblotting was performed with cytosol samples (Fig. 4b), thus indicating that Tdh2 and Tdh3 cytosolic polypeptides are also present in the cell wall, whereas Tdh1 is not detected. In agreement with previous reports, the Tdh3 polypeptide represents the major Tdh polypeptide in exponentially growing cells, whereas Tdh1 is not found, as it is synthesized only as cells enter stationary phase (Boucherie et al., 1995; McAlister \& Holland, 1985b).

In order to determine whether Tdh1 is also a cell-wallassociated polypeptide, we performed the immuno- detection by Western blotting using $\beta \mathrm{ME}$ extracts and cytosol from stationary-phase cells. Two polypeptide bands were immunodetected in the $\beta \mathrm{ME}$ extract from the $t d h 3$ mutant, one corresponding to Tdh2 (also detected in $\beta \mathrm{ME}$ extract from exponentially growing cells) and a second one, with a slightly lower apparent molecular mass, probably corresponding to Tdh1 (Fig. $4 \mathrm{c})$; both polypeptides were also detected in cytosol from $t d h 3$ stationary-phase cells (Fig. 4c). When samples from $t d h 1 t d h 3$ double mutant cells in stationary phase were analysed, only a single reactive band, corresponding to Tdh2 polypeptide, was detected in both cytosol and $\beta \mathrm{ME}$ extract (Fig. 4c). This demonstrates that the second polypeptide found in the cell wall in $t d h 3$ stationary-phase cells is encoded by the TDH1 gene, and does not originate from differential processing of the TDH2-encoded polypeptide. Tdh1 polypeptide was not detected in stationary-phase $t d h 2$ mutant cells (data not shown). In this case the pattern of reactive bands was identical to that found in exponentially growing cells (Fig. 4a, 4b), suggesting that TDH1 is not expressed in $t d h 2$ mutant cells, even in stationary phase. We conclude that the TDH1 gene, when expressed in stationaryphase cells, directs the synthesis of a polypeptide that is also located at the cell wall.

\section{DISCUSSION}

The presence of GAPDH at the microbial cell wall has been described in various prokaryotes and eukaryotes (see Introduction). Various lines of evidence indicate that GAPDH is also an autochthonous cell-wallassociated protein in $S$. cerevisiae. First, whole cells of $S$. cerevisiae possess a GAPDH activity proportional to the number of cells present, indicating the presence of active protein outside the plasma membrane. Second, a pAb anti-SC-GAPDH, which specifically recognizes by West- 
ern immunoblotting the GAPDH protein in cytosol samples, was able to label the cell surface of yeast in IIF experiments, and in addition, inhibited the detection of GAPDH activity in intact cells (up to $30 \%$ ). This indicates that GAPDH is partly located at the cell surface. Immunoelectron microscopy confirmed the presence of GAPDH at the cell surface. Third, the cell wall GAPDH has been solubilized from intact cells by $\beta M E$ treatment, a method which releases autochthonous yeast cell wall molecules without significant intracellular contamination (Chaffin et al., 1998; López-Ribot \& Chaffin, 1996).

Regenerating protoplasts of $S$. cerevisiae have been described to secrete three glycolytic proteins: enolase (Eno2), fructose biphosphate aldolase (Fba1) and GAPDH (Tdh2-3) (Pardo et al., 1999). A genetic approach has been used to demonstrate that Eno2 and Fba1, although lacking a conventional N-terminal signal sequence, are able to be secreted into the periplasmic space (Pardo et al., 1999). Furthermore, heterologous overexpression in S. cerevisiae of the Kluyveromyces marxianus GAP1 gene, encoding a GAPDH protein, results in the accumulation of GAPDH in the cell wall of yeast cells and confers a flocculent phenotype (Falcao Moreira et al., 2000), providing additional evidence of the ability of $S$. cerevisiae to target GAPDH protein, lacking N-terminal signal peptide, to the cell wall. The presence of members of the Hsp70 family (Ssa1 and Ssa2) in the cell wall of $S$. cerevisiae has been described (López-Ribot \& Chaffin, 1996), in addition to its well known cytosolic location; also members of the Hsp70 family (Ssa1, Ssa2, as well as Ssb1 and Ssb2) are secreted by regenerating protoplasts of $S$. cerevisiae (Pardo et al., 1999). Interestingly, some cytosolic proteins such as enolase, members of the Hsp70 family, and phosphoglycerate kinase, have been described to be bona fide components of the C. albicans cell wall (Alloush et al., 1997; Angiolella et al., 1996; Chaffin et al., 1998; LópezRibot et al., 1996; Martínez et al., 1998). Hence, the presence of cytosolic proteins, including glycolytic enzymes, as autochthonous microbial cell wall components, appears to be a more general phenomenon than was previously imagined (Alloush et al., 1997; Angiolella et al., 1996; Chaffin et al., 1998; Fernandes et al., 1992; Gil-Navarro et al., 1997; López-Ribot et al., 1996; López-Ribot \& Chaffin, 1996; Modun \& Williams, 1999; Pancholi \& Fischetti, 1992, 1998; Winram \& Lottenberg, 1996). All these observations favour the idea of the involvement of a nonconventional secretion mechanism for these cell-wall-associated proteins. However, the alternative possibility that they originate, at least in part, by cell leakage and release of cytosolic proteins from a small amount of damaged cells cannot be discarded, particularly in the case of Tdh polypeptides, which are abundant proteins that at acidic $\mathrm{pH}$ may bind to negatively charged molecules at the yeast cell surface.

As $S$. cerevisiae GAPDH is encoded by three structural genes (TDH1-3), we wondered whether the cell-wallassociated protein corresponded to one or more gene products. We therefore searched for the presence of cellwall-associated GAPDH in single $t d h$ mutant cells and double $(t d h 1 t d h 2$ and $t d h 1 t d h 3)$ mutants. Overall our results indicate that all three polypeptides encoded by TDH1-3 are associated with the cell wall. Tdh2 and Tdh3 are found at the cell surface of exponentially growing cells, as well as in the cytosol. The TDH1 gene, when expressed in stationary-phase cells, directs the synthesis of a GAPDH polypeptide that is located both in the cytosol and in the cell wall.

The absence of correlation between cytosolic activity and cell-wall-associated activity in $t d h$ mutants may reflect that: (i) different $T D H$ genes may possess distinct ability to direct the protein to the cell wall, (ii) the catalytic activity of individual isozymes may vary between the cytosol and the cell wall due to possible modification of polypeptides during their association with the cell wall, (iii) activity may depend on the assembly of the cell wall polypeptides into active GAPDH, a process which may differ from that of the cytosol.

Our results incorporate the GAPDH of S. cerevisiae into the newly emerging family of multifunctional cell-wallassociated GAPDHs which retain their catalytic activity, although the precise role of the cell-wall-associated GAPDH in $S$. cerevisiae physiology remains to be determined.

\section{ACKNOWLEDGEMENTS}

This work was supported by Grant PM97-0098 from the Programa Sectorial de Promoción General del Conocimiento (Ministerio de Educación y Ciencia, Spain), and Grant GV00015-5 from the Conselleria d'Educació i Ciència (Generalitat Valenciana). M.L.D. is the recipient of a predoctoral fellowship from the Ministerio de Educación y Ciencia, Spain. We thank Dr M. J. Holland (University of California, Davis) for kindly providing $S$. cerevisiae wild-type and $t d h$ mutant strains.

\section{REFERENCES}

Alloush, H. M., López-Ribot, J. L., Masten, B. J. \& Chaffin, W. L. (1997). 3-Phosphoglycerate kinase: a glycolytic enzyme protein present in the cell wall of Candida albicans. Microbiology 143, 321-330.

Angiolella, L., Facchin, M., Stringaro, A., Maras, B., Simonetti, N. \& Cassone, A. (1996). Identification of a glucan-associated enolase as a main cell wall protein of Candida albicans and an indirect target of lipopeptide antimycotics. J Infect Dis 173, 684-690.

Boucherie, H., Bataille, N., Fitch, I. T., Perrot, M. \& Tuite, M. F. (1995). Differential synthesis of glyceraldehyde-3-phosphate dehydrogenase polypeptides in stressed yeast cells. FEMS Microbiol Lett 125, 127-134.

Casanova, M. \& Chaffin, W. L. (1991). Cell wall glycoproteins of Candida albicans as released by different methods. J Gen Microbiol 137, 1045-1051.

Chaffin, W. L., López-Ribot, J. L., Casanova, M., Gozalbo, D. \& Martinez, J. P. (1998). Cell wall and secreted proteins of Candida albicans: identification, function, and expression. Microbiol Mol Biol Rev 62, 130-180. 
Charrier-Ferrara, S., Caillol, D. \& Goudot-Crozel, V. (1992). Complete sequence of the Schistosoma mansoni glyceraldehyde3-phosphate dehydrogenase gene encoding a major surface antigen. Mol Biochem Parasitol 56, 339-344.

Falcao Moreira, R., Fernandes, P. A. \& Moradas-Ferreira, P. (1998). Kluyveromyces marxianus flocculence and growth at high temperature is dependent on the presence of the protein p37. Microbiology 144, 681-688.

Falcao Moreira, R., Ferreira-Da-Silva, F., Fernandes, P. A. \& Moradas-Ferreira, P. (2000). Flocculation of Saccharomyces cerevisiae is induced by transformation with the GAP1 gene from Kluyveromyces marxianus. Yeast 16, 231-240.

Ferdinand, W. (1964). The isolation and specific activity of rabbit muscle glyceraldehyde-3-phosphate dehydrogenase. Biochem J 92, 578 .

Fernandes, P. A., Keen, J. N., Findlay, J. B. C. \& Moradas-Ferreira, P. (1992). A protein homologous to glyceraldehyde-3-phosphate dehydrogenase is induced in the cell wall of flocculent Kluyveromyces marxianus. Biochim Biophys Acta 1159, 67-73.

Gil, M. L., Villamón, E., Monteagudo, C., Gozalbo, D. \& Martínez, J.P. (1999). Clinical strains of Candida albicans express the surface antigen glyceraldehyde-3-phosphate dehydrogenase in vitro and in infected tissues. FEMS Immunol Med Microbiol 23, 229-234.

Gil-Navarro, I., Gil, M. L., Casanova, M., Martínez, J. P. \& Gozalbo, D. (1997). The glycolytic enzyme glyceraldehyde-3-phosphate dehydrogenase of Candida albicans is a surface antigen. $J$ Bacteriol 179, 4992-4999.

Goudot-Crozel, V., Caillol, D., Djabali, M. \& Dessein, A. J. (1989). The major parasite surface antigen associated with human resistence to schistosomiasis is a $37 \mathrm{kDa}$ glyceraldehyde-3phosphate dehydrogenase. J Exp Med 170, 2065-2080.

Gozalbo, D., Gil-Navarro, I., Azorín, I., Renau-Piqueras, J., Martínez, J.P. \& Gil, M. L. (1998). The cell wall associated glyceraldehyde-3-phosphate dehydrogenase of Candida albicans is also a fibronectin and laminin binding protein. Infect Immun 66, 2052-2059.

Harlow, E. \& Lane, D. (1988). Antibodies: a Laboratory Manual. Cold Spring Harbor, NY: Cold Spring Harbor Laboratory.

Laemmli, U. K. (1970). Cleavage of structural protein during the assembly of the head of bacteriophage T4. Nature 227, 680-685.

López-Ribot, J. L. \& Chaffin, W. L. (1996). Members of the hsp70 family of proteins in the cell wall of Saccharomyces cerevisiae. $J$ Bacteriol 178, 4724-4726.

López-Ribot, J. L., Alloush, H. M., Masten, B. J. \& Chaffin, W. L. (1996). Evidence for presence in the cell wall of Candida albicans of a protein related to the hsp70 family. Infect Immun 64, 3333-3340.

McAlister, L. \& Holland, M. J. (1985a). Isolation and characterization of yeast strains carrying mutations in the glyceraldehyde-3-phosphate dehydrogenase genes. J Biol Chem 260, 15013-15018.
McAlister, L. \& Holland, M. J. (1985b). Differential expression of the three yeast glyceraldehyde-3-phosphate dehydrogenase genes. J Biol Chem 260, 15019-15027.

Martínez, J. P., Gil, M. L., López-Ribot, J. L. \& Chaffin, W. L. (1998). Serologic response to cell wall mannoproteins and proteins of Candida albicans. Clin Microbiol Rev 11, 121-141.

Modun, B. \& Williams, P. (1999). The staphylococcal transferrinbinding protein is a cell wall glyceraldehyde-3-phosphate dehydrogenase. Infect Immun 67, 1086-1092.

Pancholi, V. \& Fischetti, V. A. (1992). A major surface protein on group A streptococci is a glyceraldehyde-3-phosphate dehydrogenase with multiple binding activity. J Exp Med 176, 415-426.

Pancholi, V. \& Fischetti, V. A. (1993). Glyceraldehyde-3-phosphate dehydrogenase on the surface of group A streptococci is also an ADP-ribosylating enzyme. Proc Natl Acad Sci USA 90, 8154-8158.

Pancholi, V. \& Fischetti, V. A. (1997). Regulation of the phosphorylation of human pharyngeal cell proteins by group A streptococcal surface dehydrogenase: signal transduction between streptococci and pharyngeal cells. J Exp Med 186, 1633-1643.

Pancholi, V. \& Fischetti, V. A. (1998). $\alpha$-Enolase, a novel strong plasmin(ogen) binding protein on the surface of pathogenic streptococci. J Biol Chem 273, 14503-14515.

Pardo, M., Monteoliva, L., Pla, J., Sanchez, M., Gil, C. \& Nombela, C. (1999). Two-dimensional analysis of proteins secreted by Saccharomyces cerevisiae regenerating protoplasts: a novel approach to study the cell wall. Yeast 15, 459-472.

Peñalver, M. C., O’Connor, J. E., Martínez, J. P. \& Gil, M. L. (1996). Binding of human fibronectin to Aspergillus fumigatus conidia. Infect Immun 64, 1146-1153.

Sirover, M. A. (1997). Role of the glycolytic protein, glyceraldehyde-3-phosphate dehydrogenase, in normal cell function and in cell pathology. J Cell Biochem 66, 133-140.

Sirover, M. A. (1999). New insights into an old protein: the functional diversity of mammalian glyceraldehyde-3-phosphate dehydrogenase. Biochim Biophys Acta 1432, 159-184.

Villamón, E., Gozalbo, D., Martínez, J.P. \& Gil, M. L. (1999). Purification of a biologically active recombinant glyceraldehyde3-phosphate dehydrogenase from Candida albicans. FEMS Microbiol Lett 179, 61-65.

Winram, S. B. \& Lottenberg, R. (1996). The plasmin-binding protein Plr of group A streptococci is identified as glyceraldehyde3-phosphate dehydrogenase. Microbiology 142, 2311-2320.

Winram, S. B. \& Lottenberg, R. (1998). Site-directed mutagenesis of streptococcal plasmin receptor protein (Plr) identifies the Cterminal Lys ${ }^{334}$ as essential for plasmin binding, but mutation of the plr gene does not reduce plasmin binding to group A streptococci. Microbiology 144, 2025-2035.

Received 27 July 2000; revised 9 October 2000; accepted 18 October 2000. 